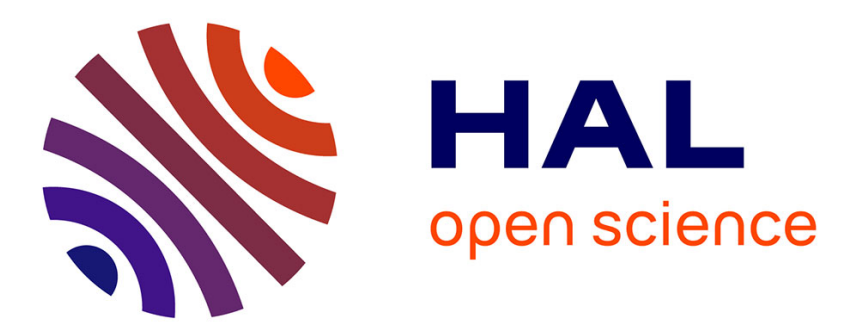

\title{
Passive coherent beam combining of quantum-cascade lasers with a Dammann grating
}

\author{
Guillaume Bloom, Christian Larat, Eric Lallier, Gaëlle Lehoucq, S.
} Bansropun, M.-S. L. Lee-Bouhours, Brigitte Loiseaux, Mathieu Carras, Xavier Marcadet, Gaëlle Lucas-Leclin, et al.

\section{To cite this version:}

Guillaume Bloom, Christian Larat, Eric Lallier, Gaëlle Lehoucq, S. Bansropun, et al.. Passive coherent beam combining of quantum-cascade lasers with a Dammann grating. Optics Letters, 2011, 36 (19), pp.3810-3812. hal-00625622

\section{HAL Id: hal-00625622 \\ https://hal-iogs.archives-ouvertes.fr/hal-00625622}

Submitted on 27 Mar 2012

HAL is a multi-disciplinary open access archive for the deposit and dissemination of scientific research documents, whether they are published or not. The documents may come from teaching and research institutions in France or abroad, or from public or private research centers.
L'archive ouverte pluridisciplinaire HAL, est destinée au dépôt et à la diffusion de documents scientifiques de niveau recherche, publiés ou non, émanant des établissements d'enseignement et de recherche français ou étrangers, des laboratoires publics ou privés. 


\title{
Passive coherent beam combining of quantum-cascade lasers with a Dammann grating
}

\author{
G. Bloom, ${ }^{1, *}$ C. Larat, ${ }^{1}$ E. Lallier, ${ }^{1}$ G. Lehoucq, ${ }^{1}$ S. Bansropun, ${ }^{1}$ M.-S. L. Lee-Bouhours, ${ }^{1}$ B. Loiseaux, ${ }^{1}$ \\ M. Carras, ${ }^{2}$ X. Marcadet, ${ }^{2}$ G. Lucas-Leclin, ${ }^{3}$ and P. Georges ${ }^{3}$ \\ ${ }^{1}$ Thales Research and Technology, 1 Avenue Augustin Fresnel, 91767 Palaiseau Cedex, France \\ ${ }^{2}$ III-V Lab, 1 Avenue Augustin Fresnel, 91767 Palaiseau Cedex, France \\ ${ }^{3}$ Laboratoire Charles Fabry de l'Institut d'Optique, CNRS, Univ Paris-Sud, 2 Avenue Augustin Fresnel, 91127 Palaiseau, France \\ ${ }^{*}$ Corresponding author: guillaume.bloom@thalesgroup.com \\ Received August 8, 2011; revised August 28, 2011; accepted August 28, 2011; \\ posted August 29, 2011 (Doc. ID 152318); published September 23, 2011

\begin{abstract}
An external cavity using a binary phase grating has been developed to achieve coherent combining of five quantumcascade lasers emitting at $4.65 \mu \mathrm{m}$. The grating phase profile is designed to combine five beams of equal intensities into a single beam with a good efficiency $(\sim 75 \%)$. The performances of this cavity concerning output power, stability, combining efficiency and beam quality are detailed. We report a CW combining efficiency of $66 \%$ corresponding to an output power of $\sim 0.5 \mathrm{~W}$ with a good beam quality $\left(M^{2}<1.6\right)$. (c) 2011 Optical Society of America

OCIS codes: $140.3298,140.5965,050.1380$.
\end{abstract}

Powerful emission in the midinfrared has recently been obtained from quantum-cascade laser (QCL) [1]. An output power of $5.1 \mathrm{~W}$ was reported in continuous wavelength $(\mathrm{CW})$ at room temperature (RT) from a single narrow-waveguide emitter [2]. Nevertheless, applications such as optical countermeasures need even higher output power with a nearly diffraction-limited beam. The external beam combining of many individual QCLs could be an interesting solution in order to fulfill these two requirements. Two methods to achieve the incoherent beam addition of QCLs have already been studied: the polarization combining [3] or the spectral beam combining $[4,5]$. In this Letter, the passive coherent beam combining (CBC) of several QCLs in external cavity is explored.

As presented in []ㅡ, we have recently developed a Michelson external cavity to achieve the CBC of two QCLs with a combining efficiency of $85 \%$ and a good beam quality. To combine more emitters, an external cavity with a $N$ to one beam combiner is designed. Such $N$ arms external cavities have already been studied: in [7], the coherent beam addition of six GaAlAs laser diodes is demonstrated with a combining efficiency of $68 \%$ and a far-field profile identical to the one of a single emitter. A five arm resonator is studied here to demonstrate the coherent beam addition of five QCLs in CW regime at RT.

The QCLs used are made of strain balanced $\mathrm{Ga}_{0.30} \mathrm{In}_{0.7} \mathrm{As} / \mathrm{Al}_{0.7} \mathrm{In}_{0.30}$ As active regions on an InP substrate. The ridge was ICP (inductively coupled plasma) etched and buried into iron doped InP by MOCVD regrowth. Electrodeposition of gold was performed for a better heat extraction. Further thermal improvement is obtained via epidown mounting on AlN submount with gold tin soldering. With a highly-reflective (HR) coating on the rear facet and no coating on the output facet, $5 \mathrm{~mm}$ long lasers exhibit $600 \mathrm{~mW}$ output power in $\mathrm{CW}$ operation at $4.65 \mu \mathrm{m}$ with a spectral bandwidth of $\sim 100 \mathrm{~nm}$ and $1.3 \mathrm{kA} . \mathrm{cm}^{-2}$ threshold current density. The five QCLs used presented different waveguide dimensions: two of them had a width of $6 \mu \mathrm{m}$ and a length of $4 \mathrm{~mm}$, two others had a width of $8 \mu \mathrm{m}$ and a length of $5 \mathrm{~mm}$, and the last one had a width of $8 \mu \mathrm{m}$ and a length of $4 \mathrm{~mm}$.
In order to prevent emission of the emitters alone in $\mathrm{CW}$ operation and thus to facilitate their phase-locking in the external cavity, their output facets were coated with an antireflection (AR) coating made of two layers of $\mathrm{SiO}_{2}$ and $\mathrm{TiO}_{2}(R<2 \%)$.

The experimental setup is presented in Fig. 1 . The external cavity extends between the rear facet of the five QCLs and the output coupler (OC). The OC is a GaAs plate presenting around $30 \%$ of Fresnel reflection with its rear facet AR coated $(R \sim 2 \%)$. Because of their high divergence angle the QCLs are individually collimated with AR coated high aperture collimation lenses (CL) from LightPath (NA $=0.86, f=1.88 \mathrm{~mm}$ ). Two gold mirrors were added in each arm to align the five beams with respect to the DG orders. Because of their intersubband lasing transition, the output emission of QCL is linearly polarized along the normal direction to the layers of the active region. This well-defined polarization will ensure that the polarization states of the five emitters can easily be made parallel which is essential for coherent coupling.

The combining of the five emitters is achieved by a binary phase grating or Dammann grating (DG) [8]. Multilevel phase gratings or continuous phase gratings present a higher efficiency, but are far more difficult to fabricate. The binary phase profile is optimized so that the grating is able to separate an incident beam at $4.65 \mu \mathrm{m}$ with a linear polarization parallel to the grooves into five beams of equal intensities with a good splitting efficiency (defined as the ratio of the power in the five central orders

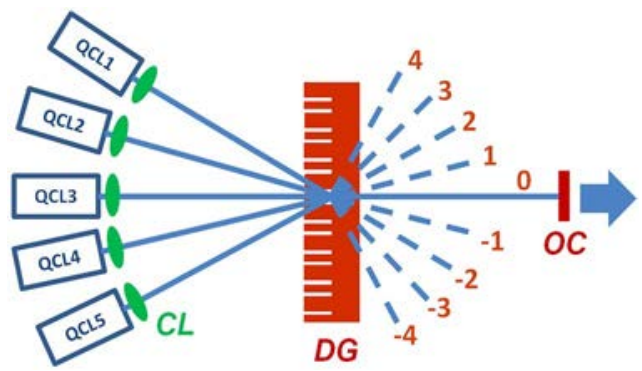

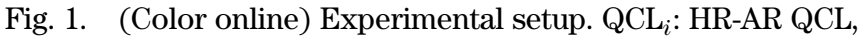
CL: collimation lens, DG: Dammann grating,OC: output coupler. 
to the incident power). The five QCLs output beams will be superimposed with the five central orders of the DG (see Fig. 1). The optimized profile is fabricated in GaAs with UV optical lithography and ICP etching (see the SEM view in Fig. 2). The grating is then AR coated on both the etched and the rear facet. An experimental splitting efficiency of $\sim 75 \%$ (the theoretical value is $77 \%$ ) is obtained along with a good uniformity between the five central orders intensities (see Fig. 2).

The CBC in $N$ arms resonator is totally passive since it is only based on loss minimization in the external cavity. As explained in [9] , the common cavity will ensure phaselocking between the different lasers and will select the proper longitudinal mode so that there are constructive interferences at the common output end (corresponding to the zeroth order of the DG) and destructive interferences on the other orders of the grating (some of them are represented by dashed lines in Fig. 1).

To maximize the combining efficiency of the DG, the intensities in the five arms should be equal. For that purpose, we need to know the current to be injected in each QCL, so they provide the same power to the five arm cavity. This question is not simple since the QCLs present different waveguide dimensions. Thus, the five QCLs are studied successively in an individual external cavity (IEC) with the same OC and the same length as in the five arm cavity. To simulate the $25 \%$ single pass losses caused by the DG, a $25 / 75$ beamsplitter was introduced in the external arm of the IEC. For a particular value $P_{\text {single }}$ of the output power of the IEC, we deduce from the previous measurements a set of five currents quite different from the others because of the different waveguide dimensions used. Thus, for $P_{\text {single }}=150 \mathrm{~mW}$, the QCLs currents are $\left[\mathrm{I}_{i}\right]=\left[\begin{array}{lllll}575 & 510 & 745 & 760 & 750\end{array}\right] \mathrm{mA}$.

Then, the five arm cavity is characterized. For a particular value $P_{\text {single }}$, a set of currents $\left[\mathrm{I}_{i}\right]$ is deduced and the output power $P_{\mathrm{CBC}}$ in the combined beam is measured. Then, this process is repeated for different values of $P_{\text {single. }}$ In Fig. $3, P_{\mathrm{CBC}}$ is represented according to $P_{\text {single }}$. The total power available from the five individual QCL taking into account the DG losses, $P_{\text {available }}=5$. $P_{\text {single }}$, is also represented. Moreover, we show on the same figure the power $P_{\text {potential }}$ that could have potentially been obtained from the five individual QCL without the $25 \%$ additional losses. $P_{\text {potential }}$ is the sum of the output powers of the IEC without the $25 / 75$ beamsplitter obtained for the same $\left[\mathrm{I}_{i}\right]$.

An output power of $0.5 \mathrm{~W}$ was obtained in $\mathrm{CW}$ regime. The output power is quite stable (relative fluctuation < $\pm 10 \%$ peak-to-peak at maximal power), at least over one
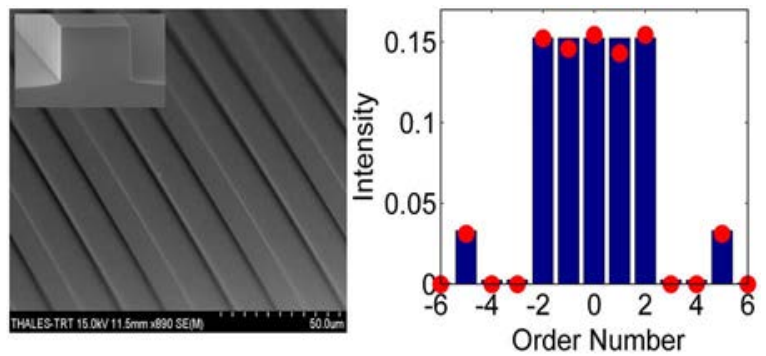

Fig. 2. (Color online) (Left) SEM view of the DG before AR coating. (Right) calculated (blue) and measured (red) orders intensities of the fabricated DG with its AR coating.

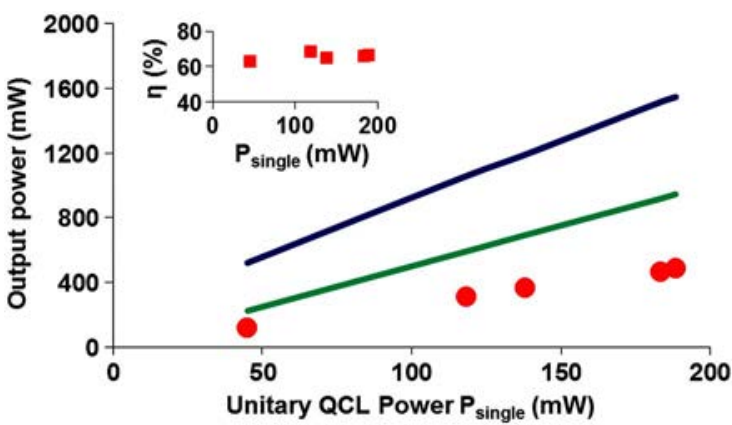

Fig. 3. (Color online) Output power versus $P_{\text {single }}$ : circles, $P_{\mathrm{CBC}}$; green solid curve, $P_{\text {available }}$; blue solid curve, $P_{\text {potential }}$. Inset: combining efficiency $\eta$ versus $P_{\text {single }}$.

hour of free running in nonprotected environment and no specific precaution (except QCL thermal stabilization). These power fluctuations were not observed when studying the CBC of two QCLs [6]. The increase of the output power fluctuations with the number of sources combined has already been described [10].

From Fig. 3, we deduce that $\sim 50 \%$ of the total available power, taking into account the DG losses, is effectively obtained in the combined beam $\left(P_{\mathrm{CBC}} / P_{\text {available }}=50 \%\right)$. Moreover, from the ratio $P_{\text {potential }} / P_{\text {available, }}$, we deduce that the use of a $100 \%$ efficiency beam combiner would have increased $P_{\mathrm{CBC}}$ by $\sim 65 \%$. Thus, far more power could be obtained by using a multilevel phase grating or a continuous phase grating.

The loss of $50 \%$ of the available power is due to the fact the DG does not work at its maximal combining efficiency. The combining efficiency of the DG is defined as $\eta=I_{0} / \sum I_{i}$ with $I_{i}$ the intensity of the $i$ th order between the DG and the OC (see Fig. 1). In Fig. 4, we show the calculated orders' intensities of a DG illuminated by five beams with the proper relative phases along with the measured ones. A combining efficiency of $\sim 66 \%$ (see the inset in Fig. 3) is measured at maximal power. It means that $66 \%$ of the incoming energy on the DG from the five QCLs is effectively coupled into the zeroth order of the DG. As explained in [9], when the phase-locking between the five arms is perfect, the combining efficiency of the cavity should theoretically be equal to the splitting efficiency of the DG, which was measured to be $\eta_{\max }=75 \%$.

We have determined two systematic errors that could explain the reduced CBC efficiency observed: the beam

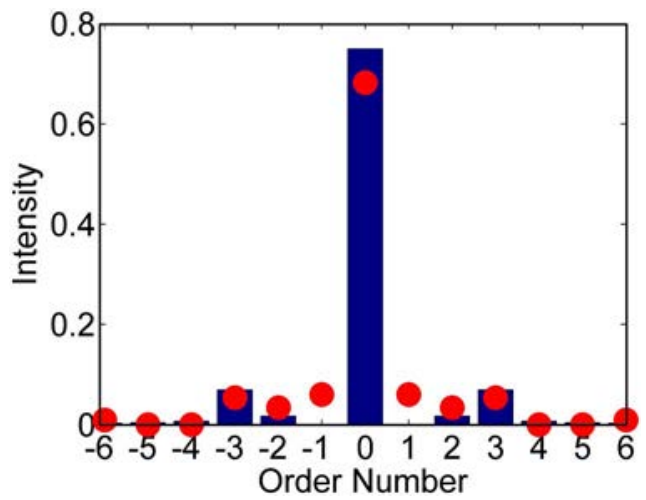

Fig. 4. (Color online) Blue: calculated orders intensities of a DG lit by five beams with the proper relative phases. Red: measured orders intensities. 


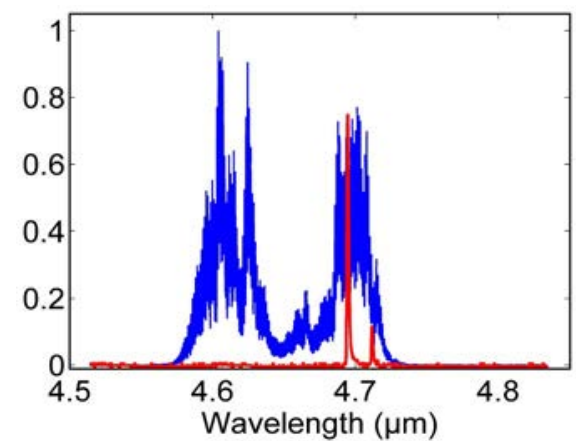

Fig. 5. (Color online) Typical spectrum of a single QCL (blue) and of the external cavity with the DG (red).

sizes error and the residual phase-mismatch between the arms. The differences between the beam sizes coming from the collimated QCLs are due to the different widths of the five QCLs waveguides. In [11], the CBC efficiency loss induced by beam profile nonuniformities is theoretically studied. In our case the combining efficiency is decreased to a value of $\eta \sim \eta_{\max } .98 \% \sim 73.5 \%$. The other systematic error considered here is the residual phasemismatches between the five arms. As explained before, passive CBC is only based on longitudinal mode selection in the $N$ arms resonator. If no common longitudinal mode (corresponding to a perfect synchronization between the $N$ arms) exists within the spectral gain bandwidth of the QCL, the system still selects the mode with the least losses. In this case, because of residual phase-mismatch between the $N$ arms, a part of the available power will be diffracted into the lossy orders of the DG, resulting in a reduced combining efficiency and thus a reduced output power [12]. If we assume a gain bandwidth of $100 \mathrm{~cm}^{-1}$ and a typical arm length of $\sim 33 \mathrm{~cm}$, we can estimate from [12] a combining efficiency of $\eta \sim \eta_{\max } .93 \% \sim 69.8 \%$. If we add the contributions of the beam size differences and imperfect phase-locking, the combining efficiency should be reduced to $\eta \sim 68.5 \%$. The value obtained with this approximate estimation of the $\mathrm{CBC}$ efficiency reduction is in good agreement with the measured combining efficiency of $66 \%$. Thus the efficiency demonstrated appears to be close to the maximal value reachable given the experimental constraints. Errors such as beam positioning error, beam pointing error, or power nonuniformities are supposed to be controlled here.

Beam quality measurements on the output beam were performed with the scanning slit method on both the slow axis (the combining direction) and on the fast axis. The combined beam was still nearly diffraction-limited since the $\mathrm{M}^{2}$ parameter (second-order moments definition) was measured to be $M_{\text {slow }}^{2}<1.2$ and $M_{\text {fast }}^{2}<1.6$. This $M^{2}$ value is very close to the one measured from the individual QCLs in external cavity $\left(M^{2}{ }_{\text {slow }}<1.2\right.$ and $M_{\text {fast }}^{2}<1.5$ ).

Finally, the spectral behavior of the cavity was analyzed using a spectrometer with a resolution of $\sim 1 \mathrm{~nm}$ (Fig. 5). The typical output spectrum presents narrow peaks spaced by $\sim 14 \mathrm{~nm}$. Compared to a single QCL typical spectrum, we observe that only a few wavelengths could oscillate in the five arm resonator. Moreover, the peaks positions in wavelength along with their relative amplitudes are observed to be highly unstable. This is due to the fact that the system is continually compensating for the perturbations from the environment.

In this Letter, the coherent beam addition of five QCLs in an external cavity using a DG was demonstrated. A power of $0.5 \mathrm{~W}$ in continuous regime at $\mathrm{RT}$ and a combining efficiency of $66 \%$ were obtained while the combined beam exhibits the same beam quality as a single emitter $\left(M^{2}<1.6\right)$. The method presented here is shown to be an efficient way to increase the brightness of QCLs and thus to address the power scaling issue in the midinfrared.

\section{References}

1. J. Faist, Science 264, 553 (1994).

2. Y. Bai, N. Bandyopadhyay, S. Tsao, S. Slivken, and M. Razeghi, Appl. Phys. Lett. 95, 221104 (2009).

3. J. Wagner, N. Schulz, B. Rösener, M. Rattunde, Q. Yang, F. Fuchs, C. Manz, W. Bronner, C. Mann, K. Köhler, M. Raab, E. Romasew, and H. D. Tholl, Proc. SPIE 7115, 71150A (2008).

4. S. Hugger, R. Aidam, W. Bronner, F. Fuchs, R. Lösch, Q. Yang, J. Wagner, E. Romasew, M. Raab, H. Tholl, B. Höfer, and A. Matthes, Opt. Eng. 49, 111111 (2010).

5. B. G. Lee, J. Kansky, A. K. Goyal, C. Pflügl, L. Diehl, M. A. Belkin, A. Sanchez, and F. Capasso, Opt. Express 17, 16216 (2009).

6. G. Bloom, C. Larat, E. Lallier, M. Carras, and X. Marcadet, Opt. Lett. 35, 1917 (2010).

7. J. R. Leger, G. J. Swanson, and W. B. Veldkamp, Appl. Phys. Lett. 48, 888 (1986).

8. H. Dammann, Opt. Acta 24, 505 (1977).

9. J. R. Leger, G. J. Swanson, and W. B. Veldkamp, Appl. Opt. 26, 4391 (1987).

10. J. Cao, J. Hou, Q. Lu, and X. Xu, J. Opt. Soc. Am. B 25, 1187 (2008).

11. G. D. Goodno, C-C. Shih, and J. E. Rothenberg, Opt. Express 18, 25403 (2010).

12. D. Kouznetsov, J. Bisson, A. Shirakawa, and K. Ueda, Opt. Rev. 12, 445 (2005). 